\title{
Looking Towards Bodzia: An Introduction
}

\author{
Andrzej Buko
}

This book presents one of the most fascinating archaeological discoveries of the post-war period in Poland: the cemetery at Bodzia in the Kuyavia region. It is one of the few cemeteries in Poland from the time of the origins of the Polish state. The unique character of this discovery is mainly due to the fact that a small, elite population was buried there. Most probably, the burials there included people whose origins were not local but were rather connected with the Slavic, nomadic Khazarian and Scandinavian milieus. ${ }^{1}$ Even though there have been many recent finds relating to the presence of foreigners in early medieval Poland, this is the first time that their traces are so prominent and so numerous.

Almost everything is unique at Bodzia: the rows of graves determined by lines of rectangular fences, the chamber grave constructions of a type known from north-western Europe, but also burial pits with annexes typical of the nomadic Khazarian milieu, the north-south orientation of the graves, which is conspicuously different from the usual alignment of contemporary graves in Poland as well as in most of Europe, and, finally, the very rich grave goods. The latter include finds with no direct analogies either in Poland or in Europe. Another important feature is the rather large number of coins deposited in graves, again a practice with no analogy in any contemporary cemetery site in Europe. Equally intriguing is the unusual chronology of those coins, as well as the specific places in which some of them were deposited inside the grave. For these reasons, for both archaeologists and historians, Bodzia represents a priceless source of information about the complex mechanisms underlying the formation of the first Piast state.

Furthermore, the Bodzia finds are interesting because of the geographical location of the site in the region of Kuyavia adjoining the route along the middle Vistula, which in the Middle Ages connected the Baltic Sea to south-eastern Europe and, farther on, to the Byzantine Empire. For many years, historians have treated the Vistula route as far less significant than those passing through Western Pomerania, famous for the Island of Wolin, often associated with the legendary Jomsborg of the Vikings. However, the most recent research has shown that the route along the Vistula River had a key role in inter-regional

1 In this case, the term 'Scandinavian' refers to individuals coming both from the west, namely from the Baltic region, broadly defined, but also from the Rus-Varangian world to the east. 
contacts, especially with Scandinavia. It is certainly not a coincidence that even before the Polish state came into being, the 'Danish' colony at Truso was established to the east of Western Pomerania, in the land of the Prussians, and continued to exist for more than two hundred years after that. Finds from the Middle and Lower Vistula region described in this publication shed new light both on the importance of this route and the rise of the medieval states in Europe.

As is often the case, the cemetery was discovered by accident during rescue excavations for a motorway. The highway covered only part of the cemetery but, as the site proved to be so important, a decision was taken to excavate the whole area using the funds of the Institute of Archaeology and Ethnology at the Polish Academy of Sciences and of the National Institute of Cultural Heritage.

This publication is designed mainly for readers outside Poland. The organization, narrative, and structure of the book have been adapted to that goal. In that respect, the book is not an excavation report (such a publication will appear in Polish), but rather a collection of chapters, combining analyses and syntheses of the source material, and discussing its significance. Their authors-eminent specialists in their subjects—formulate new hypotheses and ideas, which put the discoveries in a broader European context.

The First Part, entitled The Area of the Middle and Lower Vistula River Valley between the 1oth-11th Centuries: Archaeology and History, consists of two texts. In the first one (Chapter 1) Mateusz Bogucki discusses the key questions connected with the Middle and Lower Vistula route during the Middle and Late Viking Period in the light of the recent archaeological data. The text presents the most important discoveries made so far and describes the historical and cultural context of the problems discussed in this publication. In the second text (Chapter 2), Roman Michałowski deals with the problems connected with the origin and early stages of the first Piast state in the context of the written sources and the existing knowledge accumulated by Polish historians of the Middle Ages.

The Second Part, The Bodzia Cemetery: Site Location, Environmental Data, Graves and their Contents, is divided into four sections. In the first part (Chapter 3), Iwona Sobkowiak-Tabaka presents the site at Bodzia and briefly discusses the history of the excavations. In Chapter 4, Iwona HildebrandtRadke discusses the results of the complex deposition and post-depositional processes which influence the state of preservation of the organic remains discovered at the site, with a particular focus on the human bones. This information is pivotal for making accurate archaeological interpretation, especially 
with respect to the problem of so-called cenotaphs, i.e., burial pits in which no human remains have been found.

Complete information about those individuals buried in the cemetery may be found in the next two sections. In Chapter 5, Iwona Sobkowiak-Tabaka describes the graves and their contents, while in Chapter 6, Alicja DrozdLipińska and Tomasz Kozłowski present a tentative anthropological analysis of the population buried in Bodzia. The part concludes with a comparison of the material from Bodzia with that from other contemporary sites in Poland.

Part 3 entitled Grave Goods and their Context, presents the various categories of goods deposited in graves. A general overview of finds from the Bodzia cemetery is presented by Andrzej Buko (Chapter 7). These goods include artifacts associated with trade, as well as weapons analyzed by Michał Kara (Chapters 8, 9). Worthy of mention here are some particularly interesting finds, namely one of the few balances so far found in the Polish lands, the first ever Langsax and a sumptuous Viking sword. In Chapter 10 Władysław Duczko presents the results of the analysis of metal jewelry and dress accessories. They include finds with no known analogies, such as the silver kaptorgi with representations of birds of prey. In Chapter 11, Maria Dekówna and Tomasz Purowski present a study of the rich collection of jewelry made of glass, enamel and minerals. The section also includes the chemical analysis of silver artifacts and of gold coatings on some of the glass beads found on the site. Many of them are unique in medieval Europe. In Chapter 12, Tomasz Sawicki presents the results of the analyses of iron objects. They include a rich collection of coffin fittings and mounts, as well as their locks.

The following sections turn to leather (Anna B. Kowalska, Chapter 13), antler, as well as ceramic, wooden, and stone artifacts (Kinga Zamelska-Monczak, Chapters 14, 15). In this connection it is worth recalling the interesting issue of the symbolic funerary references ascribed to some wooden and stone containers.

A separate group of artifacts - coins-is analyzed in Chapter 16 by Stanisław Suchodolski. As already mentioned, this is a unique collection because of the number and origin of the finds, the particular places of their deposition, and the broader cultural and socio-economic connotations.

The second part of the book, Parts $4-8$, has a more synthetic character and the issues presented in it have broader contextual significance. Part 4 deals with the funerary rites and consists of three texts. In Chapter 17, Michał Kara discusses the organization of the graveyard as well as the funerary rites and ceremonies. There is an extensive discussion of the unique arrangement of the burials in rows separated by fences, the diverse forms of burials, some of which, however, resemble the chamber grave type. A separate analysis is devoted to the grave furniture, such as timber linings of the walls, biers, or 
coffins. A tentative reconstruction of the latter is presented by Tomasz Sawicki in Chapter 18 which also deals with a number of surprising analogies, both from a chronological and a geographical point of view. An interesting aspect of the burial rites is presented by Joanna Koszałka, who focused on the symbolic meaning of the timber found on the site (Chapter 19).

In Part 5, entitled Chronology of the Cemetery, Andrzej Buko and Michał Kara confront two categories of data: the absolute dating and the chronology obtained through stratigraphical and typological analysis, including the large collection of coins found in the burials (Chapter 20). These groups of data correspond very closely and indicate a surprisingly well-defined and relatively short time-span during which the cemetery remained in use.

The ethno-cultural affiliation of the deceased is one of the fundamental types of information, though usually not easily susceptible to analysis. These issues are discussed in Part 6, Locals or Aliens? Claims about the foreign affiliation of those buried in early medieval cemeteries, which are based on the observation of foreign features in the material culture, are often countered in the literature with the argument that such features are only the result of a local adoption and adaptation of foreign models of culture. In the case of Bodzia, at least, the issue is quite clear. The arguments derived from the traditional archaeological analysis were confronted with the results obtained from the analysis of strontium isotopes in the bones and with genetic tests. The principles of the method, and the results obtained from the analysis of tooth enamel are discussed in detail by T. Douglas Price and Karin Margarita Frei in Chapter 21. These results are worthy of particular attention because they disprove many of the currently held views. In turn, Wiesław Bogdanowicz, Tomasz Grzybowski and Magdalena M. Buś present in Chapter 22 the first interesting results of the tests (mtDNA and nuDNA) on the possible genetic affiliations of the deceased.

In Part 7, entitled European Contexts of the Bodzia Cemetery, Michael MüllerWille and Michał Kara place the discoveries at the Bodzia cemetery in their wider, European (Chapter 23) and Polish (Chapter 24) contexts. They provide an interesting and vivid panorama of the data as well as an unexpected conclusion concerning the direct affiliations of people buried in the cemetery. Finally, in Part 8-Bodzia Cemetery in Light of the Interdisciplinary Research - the most important findings and questions of the interdisciplinary analyses are summarized (Chapter 25).

One more issue should be addressed. The title of the book refers to the 'Late Viking Age', even though in Poland the period during which the Bodzia cemetery was in use is called 'the early state period', 'the first period of the Piast 
monarchy', or 'the period of the origins of the Polish state.' The phrase 'Late Viking Age' is commonly used in Northern European archaeology in a strictly chronological sense, namely in reference to the period between the second half of the 1oth and first half of the 11th century. This is precisely the period during which the cemetery in Bodzia was in use. 